\title{
Safety and efficacy of laropiprant and extended-release niacin combination in the management of mixed dyslipidemias and primary hypercholesterolemia
}

\author{
This article was published in the following Dove Press journal: \\ Drug, Healthcare and Patient Safety \\ 22 May 2010 \\ Number of times this article has been viewed
}

\section{Adie Viljoen' \\ Anthony S Wierzbicki \\ 'Lister Hospital, Stevenage, Hertfordshire, UK; ${ }^{2}$ Guy's and St \\ Thomas Hospitals, London, UK}

Correspondence: Adie Viljoen Lister Hospital, Stevenage, Hertfordshire SGI 4AB, UK

Tel +44 I4042345433

Email adie.viljoen@nhs.net

\begin{abstract}
Statins form the cornerstone of pharmaceutical cardiovascular disease prevention. However, despite very effective statin intervention, the majority of events remain unpreventable. In some cases statin therapy alone is insufficient to achieve adequate lipid levels whereas other patients are unable to tolerate statins. This calls for additional treatment options. Niacin has a long history of success in reducing low-density lipoprotein cholesterol and triglycerides, and increasing high-density lipoprotein cholesterol. It was the first lipid-lowering drug to demonstrate a reduction in cardiovascular events, and remains the only one that has consistently shown benefits on surrogate outcomes when added to background therapies of other lipid-lowering drugs, including statins. Niacin's uptake in clinical practice has been less successful due to its side-effect profile, most notable being flushing. The uncovering of the mechanism by which flushing is induced, together with the development of a prostaglandin $\mathrm{D}_{2}$ receptor inhibitor (laropiprant) which reduces this downstream flushing effect of niacin, has sparked new promise in therapeutic lipid management. It provides an additional treatment option into managing lipid abnormalities. The uptake in clinical practice of the niacin-laropiprant combination will depend on the relative improvements experienced by the patient in the side-effect profile compared to other treatment options, as well as on the the keenly-awaited outcome studies currently underway. Until these data become available guidelines and recommendations are unlikely to change and niacin's position in therapeutic cardiovascular risk prevention will be determined by clinician opinion and experience, and patient preferences.
\end{abstract}

Keywords: niacin, laropiprant, lipid abnormalities

\section{Introduction}

Cardiovascular disease (CVD) is the leading cause of illness and death in the world and this statistic is not projected to change in the next decade. ${ }^{1,2}$ It manifests most frequently as ischemic heart disease and cerebrovascular disease, and atherosclerosis is the primary cause of this. ${ }^{3}$ Research into understanding the underlying mechanisms of disease together with the formulation of compounds that are able address the underlying pathology has now spanned numerous decades. The fact that atherosclerotic plaque is largely made up of cholesterol has been known since the middle of the 19th century and, since then, abundant data link hypercholesterolemia to atherogenesis. ${ }^{4}$ The most extensively researched of the pharmaceutically modifiable 
risk factors is cholesterol; in particular, the lowering of low-density lipoprotein cholesterol (LDL-C) forms the primary target of focus in CVD risk prevention. ${ }^{5,6}$ Statins form the cornerstone of pharmaceutical CVD prevention, and their efficacy in reducing mortality in both primary and secondary prevention settings is beyond dispute. ${ }^{7,8}$ Over the past decade these drugs have been particularly successful in the market, growing in excess of $\$ 25$ billion. ${ }^{9}$ However despite very effective statin intervention the majority of events remain unpreventable. Around $20 \%$ of patients in the statin arm of the Heart Protection Study suffered from major cardiovascular events in 5 years, and it is reckoned that only $40 \%-50 \%$ of potential events may be prevented by statin therapy. ${ }^{10,11}$ Furthermore, statin therapy suffers from several limitations. ${ }^{4}$ These include both lack of sufficient efficacy and clinical side-effects related to their use. The treatment of 1000 patients is likely to prevent 37 events at the cost of five discontinuations due to side effects. ${ }^{12}$ The main disadvantage of statins is their shallow dose efficacy profile in that doubling the dose only results in a 5\%-7\% extra reduction in LDL-C, ${ }^{13,14}$ but this occurs with an exponential effect in increasing side effects. ${ }^{15}$ This provides the drive in the search for additional benefits beyond statin treatment.

\section{Low-density lipoprotein cholesterol and statins}

LDL is the main atherogenic lipoprotein particle and remains the primary target for lipid-lowering therapy., 5 Early epidemiological studies incriminated high levels of LDL-C as being atherogenic with the serum total cholesterol (TC) as a good correlate for LDL-C levels. ${ }^{5}$ This was followed by unequivocally demonstrating the clinical benefit of LDL-C lowering. The most notable evidence comes from the clinical trials of statins. ${ }^{7,8}$ Their primary effect on the lipid parameters is their ability to lower LDL-C. Statins act by inhibiting the enzyme 3-hydroxy-3-methylglutaryl coenzyme A (HMG $\mathrm{CoA}$ ) reductase, which catalyzes the rate-limiting step in cholesterol synthesis. Inhibition of HMG CoA reductase leads to increased expression of LDL receptors on hepatocytes with increased LDL-C uptake from the circulation. Despite being prescribed for their cholesterol-lowering effect, statins have several other advantageous pleiotropic effects countering atherosclerosis. The pleiotropic effects of statins include improvement of endothelial dysfunction, increased nitric oxide bioavailability, antioxidant properties, inhibition of inflammatory responses, and stabilization of atherosclerotic plaques. $^{10}$
Despite their success and the substantial benefits attributable to statins a significant preventable gap remains. There is also increasing demand for LDL-C reductions of more than $50 \%$, and approaching $90 \%$ in some cases of familial hypercholesterolemia, and as LDL-C targets are progressively reduced in patients with established coronary heart disease. Statins also show wide variation in dose response, ${ }^{15}$ variations in bioavailability, and no clear pharmacogenetic basis to efficacy or safety. ${ }^{16,17}$

Apart from the benefits shown following statin treatment, lowering of LDL-C seems beneficial irrespective of the method employed. ${ }^{18}$ A meta-analysis of five diet, three bile acid sequestrant, one surgery, and 10 statin trials, with 81,859 participants, showed a relationship between LDL-C lowering and reduction in cardiovascular events. ${ }^{19}$ Professional guidelines therefore focus primarily on LDL-C. ${ }^{5,6,20}$ However, demonstration of a mortality benefit is still awaited for most other therapies which lower LDL-C concentrations.

Owing to the disease burden and the substantial residual risk which remains despite statin treatment, the need exists for additional therapies. This may in part be due to the success of statin treatment, where newer agents have to show equivalent efficacy or additional benefit on the background of statin treatment, which is proving very costly in the clinical trial setting. ${ }^{21}$

\section{Niacin}

Vitamin $B_{3}$ is essential to all living cells. There are two forms of vitamin $\mathrm{B}_{3}$ : nicotinic acid (or niacin) and nicotinamide. Both the acid and the amide are precursors to the coenzyme, nicotinamide adenine dinucleotide (NAD+) and its phosphorylated form NADP, which are key factors in dehydrogenation reactions. ${ }^{22}$ These molecules are also essential components of numerous biosynthetic pathways, cell protection, and signaling mechanisms. ${ }^{23,24}$ Vitamin $\mathrm{B}_{3}$ was initially best known for its clinical manifestation as a deficiency. Deficiency of vitamin $B_{3}$ was referred to as the disease with the four 'D's': namely: dermatitis, diarrhea, dementia and death. ${ }^{25}$ Two centuries after pellagra was first described in 1735, its etiology was elucidated. It was shown that nicotinic acid could cure black tongue in dogs, which was an early animal model for pellagra. ${ }^{26}$

It was a further two decades later, in the early 1950s that the lipid-lowering effects of niacin were described by the pathologist Rudolf Altschul. ${ }^{27}$ He reported his initial findings following experiments in rabbits and then in a landmark study of its effects in humans. ${ }^{28}$ Niacin was the first medication to show notable lipid-lowering effects in 
humans. Merely a year after Altschul's report it was shown by another group that $3 \mathrm{~g}$ of nicotinic acid per day was able to reduce plasma cholesterol by $16 \%$ on average in a group of patients with familial hypercholesterolemia. ${ }^{29}$ Importantly, this study showed that the reduction in cholesterol was due to a decrease in $\beta$-lipoproteins, ie, LDL-C. Furthermore, it was also shown that the ratio of $\beta$ to $\alpha 1$-cholesterol [ie, LDL-C to high-density lipoprotein cholesterol (HDL-C)] decreased from 9.0 to 5.6 .

\section{Clinical studies with niacin}

These initial findings formed the basis for investigating the effect of lipid lowering to reduce cardiovascular events. Table 1 depicts the most notable clinical trials involving niacin. Niacin was the first lipid-lowering agent shown to significantly reduce cardiovascular events, although not in-trial mortality, in the Coronary Drug Project (CDP) which randomized 3908 men with previous myocardial infarction (MI) to either nicotinic acid or placebo. ${ }^{30}$ Major coronary heart disease (CHD) events, nonfatal MI, and cerebrovascular events were reduced by $22 \%$ but there was no effect on overall mortality.
However in the 15-year post-trial follow-up, nearly 9 years after termination of the trial, mortality from all causes was $11 \%$ lower in the nicotinic acid group. ${ }^{31}$ The other arms of the CDP using clofibrate, d-thyroxine, and estrogen showed no effect or were terminated early.

Several long-term clinical studies with nicotinic acid have demonstrated a reduction in surrogate outcomes, CHD events, and mortality, when used in combination with other lipid-modifying drugs which include colestipol (a bile acid sequestrant), ${ }^{32}$ clofibrate $^{33}$ and statins. ${ }^{34,35}$ The Cholesterol-Lowering Atherosclerosis Study (CLAS) ${ }^{32}$ was a randomized, placebo-controlled, angiographic trial testing combined colestipol hydrochloride and niacin therapy in 162 men aged 40 to 59 years with previous coronary bypass surgery. Atherosclerosis regression, as indicated by perceptible improvement in overall coronary status, occurred in $16.2 \%$ of colestipol-niacin treated men vs $2.4 \%$ placebo treated $(P=0.002)$. In the underpowered Stockholm Ischemic Heart Disease Secondary Prevention Study, 555 patients received either clofibrate and nicotinic acid, or standard treatment. ${ }^{33}$ Total mortality was 82 cases in the control group and 61

Table I Notable trials including niacin ${ }^{30,32-36,39,40}$

\begin{tabular}{|c|c|c|c|c|c|}
\hline Study & Year reported & Interventions & Number patients & Outcome measures & Note \\
\hline$\overline{C D P}$ & 1975 & $\begin{array}{l}\text { Niacin } \\
\text { Clofibrate } \\
\text { Thyroxine } \\
\text { Estrogen }\end{array}$ & 8341 & $\begin{array}{l}\text { Decreased nonfatal } \\
\text { MI for Niacin arm }\end{array}$ & $\begin{array}{l}\text { III9 patients } \\
\text { received niacin; } \\
\text { all other arms had } \\
\text { no effect or were } \\
\text { terminated early }\end{array}$ \\
\hline CLAS & 1987 & $\begin{array}{l}\text { Niacin and } \\
\text { colestipol }\end{array}$ & 162 & Coronary angiography & $\begin{array}{l}\text { Decreased } \\
\text { atherosclerosis }\end{array}$ \\
\hline S-IHD & & $\begin{array}{l}\text { Niacin and clofibrate vs } \\
\text { standard care }\end{array}$ & 555 & Overall mortality & $\begin{array}{l}\text { Not blinded } \\
\text { No placebo control } \\
\text { Underpowered }\end{array}$ \\
\hline HATS & 2001 & $\begin{array}{l}\text { Niacin and simvastatin vs } \\
\text { Antioxidants vs niacin and } \\
\text { Simvastatin and antioxidants } \\
\text { vs Placebo }\end{array}$ & 160 & $\begin{array}{l}\text { Coronary angiography } \\
\text { and MACE }\end{array}$ & $\begin{array}{l}\text { Reduction in MACE } \\
\text { on niacin and } \\
\text { simvastatin arm }\end{array}$ \\
\hline ARBITER 2 & 2004 & $\begin{array}{l}\text { Niacin vs placebo } \\
\text { Added to statin }\end{array}$ & 160 & cIMT & $\begin{array}{l}\text { cIMT progression } \\
\text { between groups was } \\
\text { not statistically } \\
\text { significant }\end{array}$ \\
\hline ARBITER 6 & 2009 & $\begin{array}{l}\text { Niacin vs ezetimibe } \\
\text { Added to statin }\end{array}$ & 208 & cIMT & $\begin{array}{l}\text { Superior efficacy of } \\
\text { Niacin over ezetimibe }\end{array}$ \\
\hline AIM HIGH & $\begin{array}{l}\text { Due to report } \\
\text { in I-2 years }\end{array}$ & $\begin{array}{l}\text { Niacin vs placebo } \\
\text { Added to statin }\end{array}$ & $\sim 3300$ & MACE & \\
\hline HPS2 - THRIVE & $\begin{array}{l}\text { Due to report } \\
\text { in } 4-5 \text { years }\end{array}$ & $\begin{array}{l}\text { Niacin and laropiprant vs } \\
\text { placebo Added to } \\
\text { simvastatin } \pm \text { ezetimibe }\end{array}$ & $\sim 28000$ & MACE & \\
\hline
\end{tabular}

Abbreviations: CDP, Coronary Drug Project; CLAS, Cholesterol-Lowering Atherosclerosis Study; S-IHD, Stockholm Ischemic Heart Disease Secondary Prevention Study; HATS, HDL-Atherosclerosis Treatment Study; ARBITER, Arterial Biology for the Investigation of the Treatment Effects of Reducing Cholesterol;AIM-HIGH, HPS2 - THRIVE, Heart Protection Study 2-Treatment of HDL to Reduce the Incidence of Vascular Events; cIMT, carotid intima media thickness; MACE, major adverse cardiovascular event. 
in the treatment group, a $26 \%$ reduction $(P<0.05)$. The main limitation of this study is that it was not blinded and was without a placebo control. The Arterial Biology for the Investigation of the Treatment Effects of Reducing Cholesterol (ARBITER) 2 study investigated the effect of niacin added to background statin treatment in patients with known CHD. ${ }^{34}$ This was a double-blind randomized placebo-controlled study involving 167 patients, and the primary endpoint was the change in common carotid intima-media thickness (cIMT) after 1 year. The overall difference in cIMT progression between the niacin and placebo groups was not statistically significant $(P=0.08)$. The HDL-Atherosclerosis Treatment Study (HATS) enrolled 160 patients who were randomly assigned to receive one of four regimens: simvastatin plus niacin, antioxidants, simvastatin-niacin plus antioxidants, or placebos. The primary end point was arteriographic evidence of a change in luminal coronary stenosis and the secondary occurrence of a first cardiovascular event. ${ }^{35}$ The study showed no effect of antioxidants but proved that patients receiving simvastatin in combination with niacin had a significant reduction in cardiovascular events but a lesser increment in HDL-C. The recently-reported ARBITER 6 study compared niacin to ezetimibe in patients who were receiving baseline statin treatment. ${ }^{36}$ The primary endpoint was the between-group difference in the change from baseline in the mean cIMT after 14 months. The trial was terminated early, on the basis of efficacy, according to a prespecified analysis conducted after 208 patients had completed the trial. As compared with ezetimibe, niacin had greater efficacy regarding the change in mean cIMT over 14 months $(P=0.003)$.

These studies either did not test the additional benefit of niacin over statin treatment or when this was attempted, such as in the ARBITER studies, the surrogate marker of cIMT was employed. Furthermore, the limitations of employing surrogate markers need to be appreciated. ${ }^{37}$ The use of the cIMTs as a surrogate marker for coronary atherosclerosis remains controversial. Although in observational studies the cIMT has been shown to predict future cardiovascular events, it is sometimes less clear what the changes in measurements under certain circumstances truly imply. ${ }^{37}$ There are therapies other than niacin that retard the progression of cIMT (ie, estrogen and thiazolidinediones) but do not reduce the incidence of cardiovascular events. ${ }^{37,38}$

These uncertainties call for outcome studies which will unequivocally demonstrate the benefit of niacin in addition to statin treatment. Fortunately, such studies are currently underway. The first is the Heart Protection Study
2-Treatment of HDL to Reduce the Incidence of Vascular Events (HPS2-THRIVE) which will evaluate niacin plus laropiprant compared to placebo in patients with established cardiovascular disease on a background of simvastatin 40 milligrams (mg) with or without ezetimibe. ${ }^{39}$ This study is currently still recruiting patients and aims to include around 28,000 individuals with a prespecified subgroup of 6000 patients with diabetes. The findings are expected to be reported in 4-5 years' time. The other outcome study underway is the Atherothrombosis Intervention in Metabolic syndrome with low HDL-Chigh triglyceride and Impact on Global Health outcomes (AIM-HIGH) which compares a modified-release niacin in patients with established coronary heart disease allied with dyslipidemia to placebo in patients already receiving simvastatin. ${ }^{40}$ This study is to include around 3300 patients and it is hoped that it will be reported in the next year. These studies will also help in casting more light on the other lipid parameters (other than LDL-C) on which niacin also has an effect.

\section{Effect of niacin and position in treatment of lipid abnormalities}

Whereas the vitamin activity of niacin, which involves cellular processes, is apparent in milligram doses, the lipid-modifying effects are seen in doses a thousand-fold greater. Owing to its favorable effects not only on LDL-C but also on HDL-C and triglycerides (TG), niacin has been referred to as the 'broad-spectrum' lipid drug. ${ }^{41}$ The magnitude of these effects can be broadly summarized by the 'rule of 20 ', namely a $20 \%$ reduction in LDL-C and TG, and a 20\% increase in HDL-C, at a dose of more than $1.5 \mathrm{~g} /$ day. ${ }^{41,42}$

Lipoproteins are complex particles and can be referred to as being heterogeneous and polydisperse..$^{43}$ Heterogeneity refers to the presence of several different subparticle classes within the lipoproteins. For example, depending on the analytical technique used, as many as 14 subfractions of high-density lipoprotein (HDL) can be distinguished. The term polydisperse indicates that each of the subclasses includes varying proportions of lipids and proteins. Around 60 protein types are associated with HDL and about 12 with LDL. ${ }^{44,45}$

\section{Low density lipoprotein}

Niacin is a potential treatment option to lower LDL-C. This could include patients on existing statin therapy where additional reduction is desired, such as patients with familial hypercholesterolemia, or in patients' intolerant to statin treatment. Not only does niacin lower LDL-C but it also has a potential further beneficial effect on LDL. Like fibrates, 
it shifts the subtype distribution by reducing the number of smaller and denser particles to ones which contain more cholesterol. ${ }^{46}$ Large numbers of studies including the Quebec Cardiovascular study have confirmed the association of small dense LDL with cardiovascular disease, which reported that men with small dense LDL particles had an increased risk of CAD compared with men with normal-sized LDL particles, independent of LDL-C, triglyceride, and the total cholesterol: HDL-C ratio. ${ }^{47,48}$ The beneficial effects of niacin may be underestimated if LDL-C is the only parameter being assessed. This potential beneficial effect of niacin is tantalizing, as no prospective studies have specifically examined whether altering particle size profiles results in benefits on cardiovascular events, though analysis of the Veterans Affairs High-Density Lipoprotein Intervention Trial (VA-HIT) study does suggest some role for this mechanism, admittedly without including non-HDL-C or apolipoprotein B in the model. ${ }^{49}$

\section{High-density lipoprotein}

Analogous to LDL, the HDL class also comprises a heterogeneous population of particles. The inverse relationship between HDL-C levels and atherosclerotic CVD provides the epidemiological basis for the widely accepted hypothesis that HDL-C is atheroprotective. ${ }^{50,51}$ Experimental studies, which include limited work on humans, have shown that HDL has several distinct but potentially overlapping atheroprotective functions. These include the well-known reverse cholesterol transport ${ }^{52}$ as well as reductions in oxidative stress and innate immune inflammation. ${ }^{53}$ More HDL-associated proteins are involved in immune/inflammatory functions than in lipid transport and metabolism, suggesting the fundamental role for HDL in innate immunity. ${ }^{44}$ Niacin is the most powerful drug currently available to raise HDL-C. Following the epidemiological evidence on HDL-C it would be intuitively reasonable to attempt to raise HDL-C with the expectation of reducing cardiovascular events. However, as opposed to LDL-C lowering, therapies to intervene in order to raise HDL-C have proven to be 'not that simple'. Some HDL therapies may reduce CVD without actually changing HDL-C concentrations. ${ }^{54}$ The intravascular ultrasound study (IVUS) of the effects of five weekly infusions of a hyper-functional apolipoprotein A-1-Milano (apoA-1) Milano, produced significant regression of coronary atherosclerosis after three months. In contrast in the Investigation of Lipid Level Management to Understand Its Impact in Atherosclerotic Events (ILLUMINATE) trial which investigated the cholesterol ester transfer protein (CETP) inhibitor, torcetrapib in 15,000 patients, HDL-C increased by $72 \%$ and
LDL-C decreased by $25 \%$, but this trial was terminated early because the treatment arm had an increase of major cardiovascular events by $25 \%$, and death from cardiovascular causes by $40 \% .{ }^{55}$ The outcome studies with niacin that are currently underway will also help answer the question on raising HDL. Analogous to the apparent improvement in the LDL profile, niacin also causes a shift in the HDL profile leading to more $\mathrm{HDL}_{2}$ (larger, cholesterol-rich particles) than $\mathrm{HDL}_{3}$ (small, lipid-poor particles). ${ }^{41}$ Whether this shift is beneficial, as is sometimes advocated, is not clear. In general, controversy still exists in regard to whether the anti-atherogenic effect of HDL can be attributed to one or both HDL subfractions, and what is the relative importance of $\mathrm{HDL}_{2}$ and $\mathrm{HDL}_{3}$ cholesterol. ${ }^{56}$ In the Kuopio Study ${ }^{57}$ and Quebec City Suburbs Study, ${ }^{58}$ $\mathrm{HDL}_{2}$ was inversely associated with $\mathrm{CHD}$, whereas $\mathrm{HDL}_{3}$ had a stronger inverse association with CHD in the Physician's Health Study ${ }^{59}$ and the 9-year follow-up of the Caerphilly study. ${ }^{56,60}$ These differences in the results of various studies may be attributable to the different assay methods used, to ethnic variations, or to the probable heterogeneity of the subfractions with different physiological functions. ${ }^{56}$

\section{Triglycerides}

Niacin generally reduces triglyceride levels by $15 \%$ to $25 \%$ in a dose-dependent manner, with the triglyceride-reduction effects seeming to parallel its action in raising HDL-C. ${ }^{41,61,62}$ It is well-established that elevated serum TG levels are associated with increased risk for atherosclerotic events. ${ }^{63}$ However to prove its causality is more difficult, and directly targeting TG in curbing cardiovascular disease is more controversial. ${ }^{62,64}$ As high serum TG levels tend to 'keep bad company', being associated with abnormal lipoprotein metabolism, as well as with other cardiovascular risk factors including obesity, insulin resistance, diabetes mellitus, and lowered levels of HDL-C, it becomes more difficult to distinguish between cause and effect. Some causes of hypertriglyceridemia have no apparent effect on atherosclerotic vascular disease, making it difficult to prove that elevated TGs are a risk factor, as opposed to being an innocent bystander. ${ }^{62,6}$ Despite no clear consensus on the benefits of directly targeting hypertriglyceridemia to reduce CVD, it is generally recommended to reduce significantly-elevated triglyceride concentrations in order to reduce the risk of pancreatitis. ${ }^{66,67}$

\section{Lp(a) lipoprotein}

$\mathrm{Lp}$ (a) lipoprotein is a lipoprotein of unknown physiologic function that is composed of apolipoprotein B-100 to which apolipoprotein(a) is covalently bound. ${ }^{68}$ Elevated plasma 
Lp(a) lipoprotein concentrations are associated with $\mathrm{CHD}{ }^{69}$ A key unresolved question is whether an elevated plasma level is the cause or the consequence of CAD, but recent epidemiological and genetic data suggest the hypothesis that lowering the plasma $\mathrm{Lp}(\mathrm{a})$ lipoprotein concentration by pharmacological means may lower the risk of CAD. ${ }^{70-72}$ These recent findings have generated renewed interest in this molecule as a potential therapeutic target. The only currently approved agent to effectively lower Lp(a) lipoprotein levels is niacin. Other drugs in development (including anacetrapib-a CETP inhibitor, mipomersen - an antisense oligonucleotide directed against apolipoprotein B-100 and thyroid analogues) are also able to significantly reduce Lp(a) lipoprotein levels.

\section{Position of niacin in treating hypercholesterolemia}

From this it is clear that niacin has an advantageous effect on most lipid parameters. As statins form the mainstay of CVD risk prevention, other treatment options are generally only considered as add-on treatment to statins. Only in cases where patients are either intolerant to statins, or when statins are contraindicated, or in cases where the primary abnormality is that of hypertriglyceridemia, nonstatin treatments are considered as first line treatments. ${ }^{5,73}$ In cases where statins are not considered as the front line treatment, there is no clear guidance which drug is the best alternative, nor is there clear guidance on which treatment should follow statin treatment. Currently the only other treatment options include: fibrates, bile acid sequestrants and ezetimibe. As is the case with niacin, none of these therapies have outcome data when combined with statins..$^{5,6}$

\section{Mechanism of action}

The mechanism by which niacin affects plasma lipids is not completely understood. ${ }^{73,74}$ The basic mechanism for the lipid-modifying effects of nicotinic acid has previously been attributed to its inhibition of lipolysis in adipose tissue. ${ }^{75}$ The reduction in free fatty acids liberated from adipose tissue results in a reduction of hepatic triglycerides available for very low density lipoprotein and LDL synthesis. More than 40 years ago Carlson described how nicotinic acid is rapidly taken up and preferentially accumulates in the adipose tissue. ${ }^{76}$ This mechanism was supported by the discovery of a specific high-affinity receptor on the membranes of adipocytes. $^{77}$ This is a G-protein coupled receptor known as GPR109A but later specific GPR109A agonist showed no effects on lipids. This is only one of the potential mechanisms by which nicotinic acid may affect lipids, and it is now believed that physiologically and clinically, this pathway may be only a minor factor in explaining the lipid effects of niacin. ${ }^{78} \mathrm{New}$ findings indicate that niacin directly and noncompetitively inhibits hepatocyte diacylglycerol acyltransferase-2 (DGAT-2), a key enzyme for TG synthesis. The inhibition of TG synthesis by niacin results in accelerated intracellular hepatic apolipoprotein $B$ degradation and the decreased secretion of VLDL and LDL particles. ${ }^{78}$ Niacin also retards the hepatic catabolism of apolipoprotein A-I which explains the increases in HDL half-life and concentrations of lipoprotein A-I HDL subfractions, which augment reverse cholesterol transport. ${ }^{78}$

\section{Safety and side effects of niacin}

Despite its ability to significantly improve all these lipid parameters, relatively few clinicians resort to niacin as a treatment option. Apart from lacking evidence in demonstrating a benefit on all cause mortality its use is also hampered by its side-effect profile. One in depth report on the discontinuation of lipid-modifying drugs in clinical practice gauged the one-year adjusted cumulative incidence of discontinuation for extended-release (ER) niacin to be $55.4 \% .{ }^{79}$ This may not sound that encouraging, but the same study also found the adjusted cumulative incidence of discontinuation was $28.9 \%$ in statin users. The most notable side-effect leading to discontinuation of niacin is flushing. This side effect, although harmless, strongly affects patient compliance. Nicotinic acid was initially used as plain nicotinic acid, in crystalline immediate release form. In an attempt to minimize flushing, various release formulations were developed. Initially, a sustained release formulation was developed but this was associated with hepatotoxicity and its clinical use was abandoned. A prolonged release formulation, known as ER niacin (marketed as Niaspan) was developed. This compound has absorption rates between plain nicotinic acid and sustained release forms, while having equivalent efficacy to alter lipid parameters. ${ }^{80,42}$ As the overall safety profile of this formulation is significantly better compared to other nicotinic acid formulations, it is the form that is now being evaluated in the ongoing outcome studies. In particular, the ER form does not raise particular concerns related to hepatotoxicity. In a 59-week-study which evaluated once-daily dosing ER niacin, only two subjects out of 723 had aspartate aminotransferase (AST) levels $>3$ times the upper limit of normal (ULN) and no subjects with alanine aminotransferase (ALT) $>3$ times ULN. ${ }^{81}$ Trials involving the combination of ER niacin and a 
statin show neither evidence of hepatotoxicity nor signs of potentiating statin-induced myopathies. ${ }^{82-84}$

The other notable potential harmful effect of niacin is that it induces elevations of glucose in a dose-dependent manner. The mechanism by which this occurs is also not well understood, but it is thought to be related to its action on free fatty acids. In a study which investigated the efficacy, safety, and tolerability of once-daily ER niacin for the treatment of dyslipidemia associated with type 2 diabetes it was found that at week 16 the HbAlc did show an increase. This change wasn't statistically significant in the $1 \mathrm{~g}$ group, but the increase from $7.2 \%$ to $7.5 \%$ in the $1.5 \mathrm{~g}$ group was statistically and possibly clinically significant. ${ }^{85}$ Analysis of data from the CDP showed that regardless of how patients were grouped, niacin appeared as effective in lowering cardiovascular outcomes in patients with hyperglycemia as it is in patients with normoglycemia. ${ }^{86}$ The current Position Statement from the American Diabetes Association suggests the use of nicotinic acid as an option in treating lipoprotein fractions other than LDL-C. It reports that

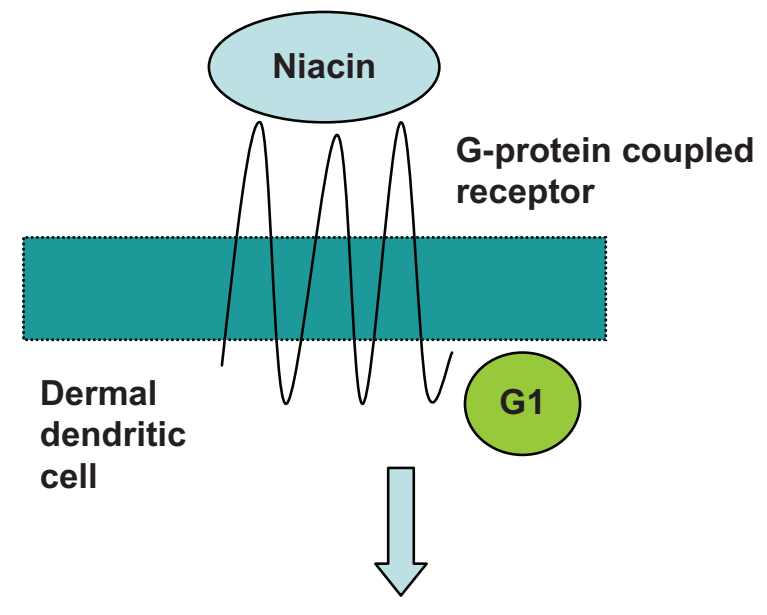

Arachidonic acid

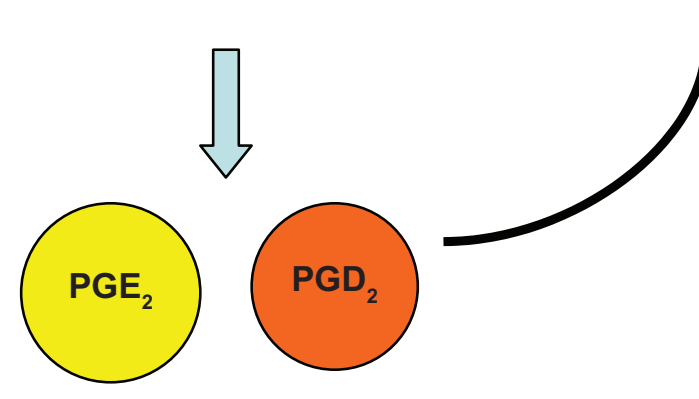

only modest changes in glucose occur and that these are generally amenable to adjustment of diabetes therapy. ${ }^{87}$ A previous statement ${ }^{88}$ discouraged its routine use, as do the recent UK-based National Institute of Health and Clinical Excellence guidelines for management of diabetes. ${ }^{89}$

Despite its having a better side-effect profile compared to the other forms of niacin, the discontinuation rate of the ER niacin still remains significant. The uncovering of the mechanism by which flushing is induced has sparked new promise into therapeutic lipid management. ${ }^{84,90}$ In general, flushing symptoms can occur following vasodilatation of small capillaries under the skin, a response that can be mediated via histamine/bradykinin or prostaglandins (PGs). This side-effect is not unique to niacin but is also seen with other drugs such as selective serotonin reuptake inhibitors. ${ }^{84}$ The flushing of niacin is not believed to be via histamine/bradykinin pathways, but rather via PGs. The G-protein-coupled receptor GRP109A, seen in adipocytes, also exists on dermal dendritic cells. Activation of the receptor on these cells induces the mobilization of

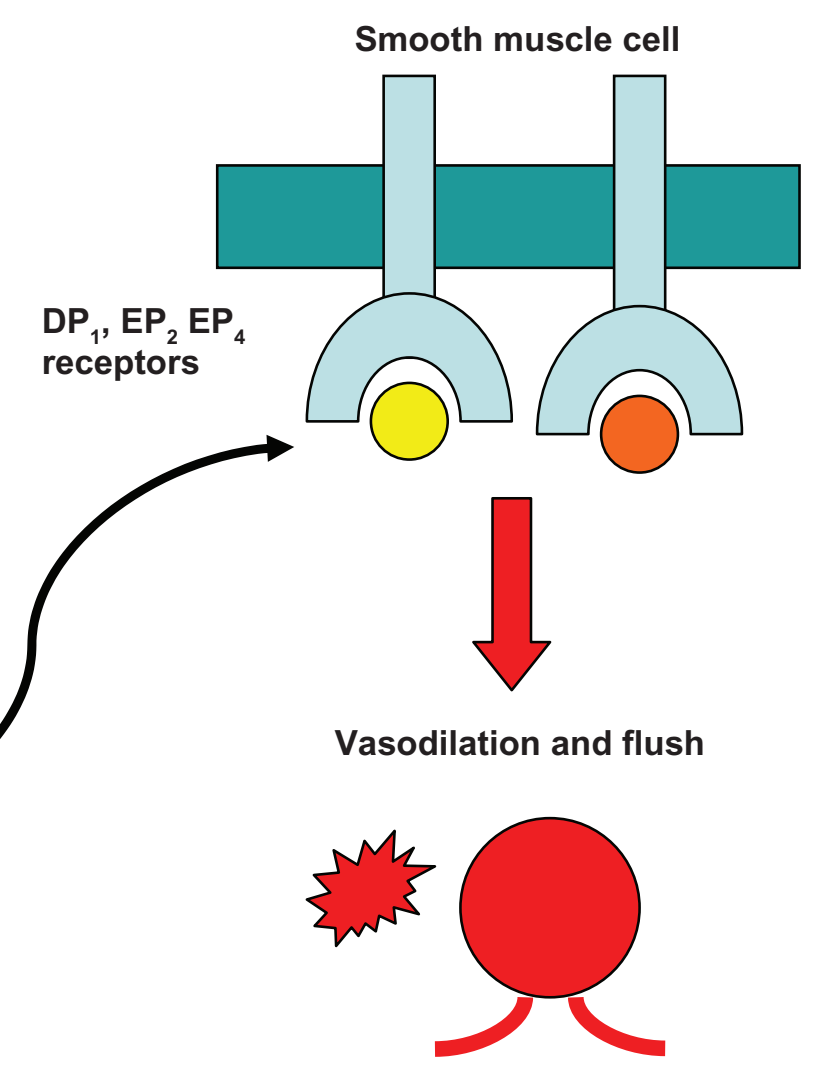

Figure I Schematic illustration of the mechanism by which niacin induces flushing. Abbreviation: PG, prostaglandin. 
arachidonic acid which leads to its conversion to, amongst other effects, the production of vasodilatory PGs, specifically forms $\mathrm{D}_{2}$ and $\mathrm{E}_{2}$. These PGs cause their effects by acting in particular through the $\mathrm{DP}_{1}, \mathrm{EP}_{2}$, and $\mathrm{EP}_{4}$ receptors. ${ }^{84,90}$ Figure 1 illustrates schematically the mechanism by which niacin induces flushing. Considering the advantageous effects of niacin, strategies to improve patient compliance by reducing flushing are important. This can be managed by various approaches namely: dose titration, patient education and additional pharmacological therapies. ${ }^{84}$ Nonsteroidal anti-inflammatory drugs are a logical treatment option as they are able to decrease the production of multiple prostaglandins by inhibiting cyclooxygenase and endoperoxidase (also referred to as $\mathrm{COX}){ }^{84,91}$

\section{Laropiprant}

Mitigation of the downstream flushing effect of niacin by blockade of the PG receptors is another potential treatment option. The discovery of a selective $\mathrm{DP}_{1}$ antagonist, MK-0542 (also known as laropiprant), was recently described, and combination of laropiprant with ER niacin has gained approval in Europe. ${ }^{92}$ Interestingly laropiprant was initially investigated as a treatment option for allergic rhinitis. ${ }^{92,93}$ Laropiprant is primarily metabolized by liver glucuronidation. ${ }^{94}$ Laropiprant has detectable off-target antagonist effects at the thromboxane A receptor, but no clinically significant effect on collagen-induced platelet aggregation, or bleeding times, with multiple doses up to $200 \mathrm{mg}$ which is five times lower than the current dose regimen. ${ }^{95}$ Table 2 depicts the notable clinical trials of niacin/laropiprant combination in patients with mixed dyslipidemias and primary hypercholesterolemia. Laropiprant does not seem to alter the lipid-modifying effect of niacin or statins. ${ }^{96,97}$ In a randomized controlled trial which consisted of three arms: placebo, ER niacin, and the combination of ER niacin with laropiprant, the combination lowered LDL-C by $18 \%$, triglycerides by $25 \%$ and increased HDL-C by $20 \%$, which was similar to ER niacin only. ${ }^{96}$ This trial, along with several others, ${ }^{98,99}$ clearly demonstrated the attenuation of flushing with laropiprant. In this 24-week study the discontinuation due to flushing was $10 \%$ in the combination group versus $22 \%$ in the ER niacin group without laropiprant, compared to $0.7 \%$ in the placebo group..$^{96}$

In April 2008, the Food and Drug Administration (FDA) rejected the licensing application of the laropiprant/niacin combination which has lead to much speculation. ${ }^{100}$ The FDA has however approved combinations of ER niacin with both simvastatin and lovastatin. Therefore the hesitancy to license this new combination may be related to laropiprant. Laropiprant is a first-in-class compound. Recently there has been increased skepticism and debate about surrogate markers in the field of lipids and diabetes which may have tipped the scales towards conservatism and a demand for outcome data. ${ }^{37}$ Most would regard the FDA review process as highly

Table 2 Notable studies with niacin/laropiprant combination in patients with mixed dyslipidemias and primary hypercholesterolemia ${ }^{96-98}$

\begin{tabular}{|c|c|c|c|c|c|}
\hline Study & $\begin{array}{l}\text { Year reported } \\
\text { reference }\end{array}$ & Interventions & $\begin{array}{l}\text { Number of patients } \\
\text { study duration }\end{array}$ & $\begin{array}{l}\text { Outcome } \\
\text { measures }\end{array}$ & Note \\
\hline $\begin{array}{l}\text { Efficacy and tolerability } \\
\text { of ER niacin/laropiprant }\end{array}$ & 2008 Reference 96 & $\begin{array}{l}\text { - ER niacin } \\
\text { - ER niacin and Laropiprant } \\
\text { - Placebo }\end{array}$ & $\begin{array}{l}n=1613 \\
6 \text { months }\end{array}$ & $\begin{array}{l}\text { - Lipid parameters } \\
\text { - Flushing }\end{array}$ & $\begin{array}{l}\text { Discontinuation due } \\
\text { to flushing: } \\
\text { - } \text { ER niacin }=22 \% \\
\text { - ER niacin and } \\
\text { Laropiprant }=10 \% \\
\text { - Placebo }=1 \%\end{array}$ \\
\hline $\begin{array}{l}\text { ER niacin/laropiprant } \\
\text { and simvastatin versus } \\
\text { ER niacin/laropiprant } \\
\text { or simvastatin }\end{array}$ & 2009 Reference 97 & $\begin{array}{l}\text { - ER niacin and Laropiprant } \\
\text { plus simvastatin } \\
\text { - ER niacin and Laropiprant } \\
\text { - Simvastatin }\end{array}$ & $\begin{array}{l}\mathrm{n}=1398 \\
3 \text { months }\end{array}$ & - Lipid parameters & $\begin{array}{l}\text { \% Reduction LDL-C } \\
\text { - ER niacin and } \\
\text { Laropiprant plus } \\
\text { simvastatin }=47 \% \\
\text { - ER niacin and } \\
\text { Laropiprant }=17 \% \\
\text { - Simvastatin }=37 \%\end{array}$ \\
\hline $\begin{array}{l}\text { Flushing profile of ER } \\
\text { niacin/laropiprant } \\
\text { versus gradually } \\
\text { titrated niacin ER }\end{array}$ & 2009 Reference 98 & $\begin{array}{l}\text { - ER niacin } \\
\text { - ER niacin and Laropiprant }\end{array}$ & $\begin{array}{l}\mathrm{n}=1455 \\
4 \text { months }\end{array}$ & $\begin{array}{l}\text { - Safety and } \\
\text { tolerability } \\
\text { - Flushing }\end{array}$ & $\begin{array}{l}\text { Discontinuation due } \\
\text { to flushing: } \\
\text { - ER niacin }=12 \% \\
\text { - ER niacin and } \\
\text { Laropiprant }=7 \%\end{array}$ \\
\hline
\end{tabular}

Abbreviations: ER, extended release; LDL-C, low density lipoprotein cholesterol. 
successful, however it is not without its limitations of gaps, tensions and conflicts. ${ }^{101}$

\section{Conclusion}

Niacin has a long history of success in reducing LDL-C and TGs and increasing HDL-C. It was the first lipid-lowering drug to demonstrate a reduction in CVD events, and remains the only one that has consistently shown benefits on surrogate outcomes when added to background therapies of other lipid-lowering drugs including statins. Despite its ability to significantly improve all these lipid parameters, relatively few clinicians resort to niacin as a treatment option. Apart from lacking evidence in demonstrating a benefit on all cause mortality and on CVD events on the background of statin therapy, its use has been hampered by its side-effect profile. The most notable side-effect of niacin is flushing. This is significant enough to cause discontinuation in up to $50 \%$. More modern formulations of intermediate-release niacin show reduced side-effects but are still limited by relatively high discontinuation rates. The recent formulation of intermediate-release niacin with a prostaglandin $\mathrm{D}_{2}$ receptor inhibitor (laropiprant) has become available, and provides a definite improvement on the side-effect profile, as well as patient compliance to treatment. Whether this reduced rate of side-effects is acceptable today is uncertain, as patients complain about statins which have side-effect rates which are still lower. The other lipid-modifying properties of niacin are probably advantageous; however controversy remains as to the direct benefits of raising HDL-C and lowering TGs. Given these considerations, guidelines are unlikely to change until the niacin-statin endpoint trials are completed. The question as to the height of the bar for drug licensing sparks a lot of debate and there has been a shift which demands longer studies, more data and better-quality data prior to licensing. ${ }^{102}$ The balance between causing harm, and potentially denying a patient useful treatment is delicate. The evaluation remains complex, and this requires clinical acumen.

\section{Declaration of interest}

Drs Wierzbicki and Viljoen have received grant support, lecture honoraria, and travel grants from Abbott, AstraZeneca, Fournier-Solvay, GlaxoSmithKline, Merck kGA, MerckSharp and Dohme, Pfizer, Sanofi-Aventis and Takeda pharmaceuticals. Dr Wierzbicki was a member of the technology appraisal committee for ezetimibe and the familial hypercholesterolemia guideline development group at the National Institute of Health and Clinical Excellence. The authors report no conflicts of interest in this work.

\section{References}

1. World Health Organization. The top 10 causes of death. [Fact sheet $\mathrm{N}^{\circ} 310$ ]; 2007 [cited Jan 2010]. Available from: http://www.who. int/mediacentre/factsheets/fs310/en/index.html

2. Murray CJ, Lopez AD. Alternative projections of mortality and disability by cause 1990-2020: Global Burden of Disease Study. Lancet. 1997;349:1498-1504.

3. Lusis AJ. Atherosclerosis. Nature. 2000 Sep 14;407:233-241.

4. Viljoen A. New approaches in the diagnosis of atherosclerosis and treatment of cardiovascular disease. Recent Pat Cardiovasc Drug Discov. 2008;3:84-91.

5. Third Report of the National Cholesterol Education Program (NCEP) Expert Panel on Detection, Evaluation, and Treatment of High Blood Cholesterol in Adults (Adult Treatment Panel III): final report. Circulation. 2002;106:3143-3421.

6. British Cardiac Society, British Hypertension Society, Diabetes UK; HEART UK, Primary Care Cardiovascular Society, Stroke Association. JBS 2: Joint British Societies' guidelines on prevention of cardiovascular disease in clinical practice. Heart. 2005;91 Suppl 5: $\mathrm{v} 1-\mathrm{v} 52$.

7. Baigent C, Keech A, Kearney PM, et al. Efficacy and safety of cholesterol-lowering treatment: prospective meta-analysis of data from 90,056 participants in 14 randomised trials of statins. Lancet. 2005;366:1267-1278.

8. Kearney PM, Blackwell L, Collins R, et al. Efficacy of cholesterollowering therapy in 18,686 people with diabetes in 14 randomised trials of statins: a meta-analysis. Lancet. 2008;371:117-125.

9. Kidd J. Life after statin patent expiries. Nat Rev Drug Discov. 2006;10:813-814.

10. Davignon J. Beneficial cardiovascular pleiotropic effects of statins. Circulation. 2004;109(23 Suppl 1):III39-III43.

11. MRC/BHF Heart Protection Study of cholesterol lowering with simvastatin in 20,536 high-risk individuals: a randomised placebocontrolled trial. Lancet. 2002;360:7-22.

12. Libby P. The forgotten majority: unfinished business in cardiovascular risk reduction. J Am Coll Cardiol. 2005;46:1225-1228.

13. Silva MA, Swanson AC, Gandhi PJ, et al. Statin-related adverse events: a meta-analysis. Clin Ther. 2006;28:26-35.

14. Stein EA, Lane M, Laskarzewski P. Comparison of statins in hypertriglyceridemia. Am J Cardiol. 1998;81:66B-69B.

15. Jones PH, Davidson MH, Stein EA, et al. Comparison of the efficacy and safety of rosuvastatin versus atorvastatin, simvastatin, and pravastatin across doses (STELLAR* Trial). Am J Cardiol. 2003;92:152-160.

16. Caslake MJ, Packard CJ. Phenotypes, genotypes and response to statin therapy. Curr Opin Lipidol. 2004;15:387-392.

17. Maitland-van der Zee AH, Boerwinkle E. Pharmacogenetics of response to statins: where do we stand? Curr Atheroscler Rep. 2005;7: 204-208.

18. Viljoen A, Wierzbicki AS. Enhanced LDL-C reduction: lower is better. Does it matter how? Int J Clin Pract. 2008;62:518-520.

19. Robinson JG, Smith B, Maheshwari N, Schrott H. Pleiotropic effects of statins: benefit beyond cholesterol reduction? A meta-regression analysis. J Am Coll Cardiol. 2005;46:1855-1862.

20. Graham I, Atar D, Borch-Johnsen K, et al. European guidelines on cardiovascular disease prevention in clinical practice: executive summary: Fourth Joint Task Force of the European Society of Cardiology and Other Societies on Cardiovascular Disease Prevention in Clinical Practice. Eur Heart J. 2007;28:2375-2414.

21. Garber AM. An uncertain future for cardiovascular drug development? N Engl J Med. 2009;360:1169-1171.

22. Sauve AA. NAD+ and vitamin B3: from metabolism to therapies. J Pharmacol Exp Ther. 2008;324:883-893.

23. Berg JM, Tymoczko JL, Stryer L, editors. Biochemistry, 5th ed. New York: W.H. Freeman and Company, 2002.

24. Viljoen A. Resurrecting an old drug - a flash in the pan or here to stay? Int J Clin Pract. 2009;63:3-6. 
25. Hegyi J, Schwartz R, Hegyi V. Pellagra: dermatitis, dementia, and diarrhoea. Int J Dermatol. 2004;43:1-5.

26. Koehn CJ, Elvehjem CA. Further studies on the concentration of the antipellagra factor. J Bio Chem. 1937;118:693-699.

27. Altschul R, Herman IH. Influence of oxygen inhalation on cholesterol metabolism. Arch Biochem Biophys. 1954;51:308-309.

28. Altschul R, Hoffer A, Stephen JD. Influence of nicotinic acid on serum cholesterol in man. Arch Biochem. 1955;54:558-559.

29. Parsons WB, Achor RW, Berge KG, McKenzie BF, Barker NW. Changes in concentration of blood lipids following prolonged administration of large doses of nicotinic acid to persons with hypercholesterolemia: preliminary observations. Proc Staff Meet Mayo Clin. 1956;31:377-390.

30. The Coronary Drug Project Research Group. Clofibrate and niacin in coronary heart disease. JAMA. 1975;231:360-381.

31. Canner PL, Berge KG, Wenger NK, et al. Fifteen year mortality in Coronary Drug Project patients: long-term benefit with niacin. $J$ Am Coll Cardiol. 1986;8:1245-1255.

32. Blankenhorn DH, Nessim SA, Johnson RL, Sanmarco ME, Azen SP, Cashin-Hemphill L. Beneficial effects of combined colestipol-niacin therapy on coronary atherosclerosis and coronary venous bypass grafts. JAMA. 1987;257:3233-3240.

33. Carlson LA, Rosenhamer G. Reduction of mortality in the Stockholm Ischaemic Heart Disease Secondary Prevention Study by combined treatment with clofibrate and nicotinic acid. Acta Med Scand. 1988;223: 405-418.

34. Taylor AJ, Sullenberger LE, Lee HJ, Lee JK, Grace KA. Arterial Biology for the Investigation of the Treatment Effects of Reducing Cholesterol (ARBITER) 2: a double-blind, placebo-controlled study of extended-release niacin on atherosclerosis progression in secondary prevention patients treated with statins. Circulation. 2004;110: 3512-3517.

35. Brown BG, Zhao XQ, Chait A, et al. Simvastatin and niacin, antioxidant vitamins, or the combination for the prevention of coronary disease. N Engl J Med. 2001;345:1583-1592.

36. Taylor AJ, Villines TC, Stanek EJ, et al. Extended-release niacin or ezetimibe and carotid intima - media thickness. $N$ Engl $J$ Med. 2009;361:2113-2122.

37. Wierzbicki AS. Surrogate markers, atherosclerosis and cardiovascular disease prevention. Int J Clin Pract. 2008;62:981-987.

38. Blumenthal RS, Michos ED. The HALTS trial - halting atherosclerosis or halted too early? N Engl J Med. 2009;361:2178-2180.

39. National Heart Lung and Blood Institute. Treatment of HDL to Reduce the Incidence of Vascular Events HPS2-THRIVE. ClinicalTrials.gov. [Online]. 2008 October 15. [cited January 2010] Available from URL: http://clinicaltrials.gov/ct2/show/NCT00461630

40. National Heart Lung and Blood Institute. Niacin plus statin to prevent vascular events: AIM-HIGH. ClinicalTrials.gov. [Online]. 2008 September 30. [cited October 30 2008] Available from URL: http:// www.clinicaltrials.gov/ct/show/NCT00120289

41. Carlson LA. Nicotinic acid: the broad-spectrum lipid drug. A 50th anniversary review. J Intern Med. 2005;258:94-114.

42. Carlson LA. Niaspan, the prolonged release preparation of nicotinic acid (niacin), the broad-spectrum lipid drug. Int J Clin Pract. 2004;58:706-713.

43. Warnick GR, Nauck M, Rifai N. Evolution of methods for measurement of HDL-cholesterol: From ultracentrifugation to homogeneous assays. Clin Chem. 2001;47:1579-1596.

44. Vaisar T, Pennathur S, Green PS, et al. Shotgun proteomics implicates protease inhibition and complement activation in the antiinflammatory properties of HDL. J Clin Invest. 2007;117:746-756.

45. Karlsson H, Leanderson P, Tagesson C, et al. Lipoproteomics I: mapping of proteins in low-density lipoprotein using two dimensional gel electrophoresis and mass spectrometry. Proteomics. 2005;5:551565.

46. Van JT, Pan J, Wasty T, et al. Comparison of extended-release niacin and atorvastatin monotherapies and combination treatment of the atherogenic lipid profile in diabetes mellitus. Am J Cardiol. 2002;89:1306-1308.
47. St-Pierre AC, Cantin B, Dagenais GR, et al. Low-density lipoprotein subfractions and the long-term risk of ischemic heart disease in men: 13-year follow-up data from the Quebec Cardiovascular Study. Arterioscler Thromb Vasc Biol. 2005;25:553-559.

48. Rizzo M, Berneis K. Low-density lipoprotein size and cardiovascular risk assessment. $Q J M$. 2006;99:1-14. Erratum in: $Q J M$. 2007;100:147.

49. Otvos JD, Collins D, Freedman DS, et al. Low-density lipoprotein and high-density lipoprotein particle subclasses predict coronary events and are favorably changed by gemfibrozil therapy in the Veterans Affairs High-Density Lipoprotein Intervention Trial. Circulation. 2006;113:1556-1563.

50. Abbott RD, Wilson PW, Kannel WB, Castelli WP. High density lipoprotein cholesterol, total cholesterol screening, and myocardial infarction. The Framingham Study. Arteriosclerosis. 1988;8: 207-211.

51. Boden WE. High-density lipoprotein cholesterol as an independent risk factor in cardiovascular disease: assessing the data from Framingham to the Veterans Affairs High-Density Lipoprotein Intervention Trial. Am J Cardiol. 2000;86:19L-22L.

52. Cuchel M, Rader DJ. Macrophage reverse cholesterol transport: key to the regression of atherosclerosis? Circulation. 2006;113:2548-2455.

53. Barter P. Effects of inflammation on high-density lipoproteins. Arterioscler Thromb Vasc Biol. 2002;22:1062-1063.

54. Nissen SE, Tsunoda T, Tuzcu EM, et al. Effect of recombinant ApoA-I Milano on coronary atherosclerosis in patients with acute coronary syndromes: a randomized controlled trial. JAMA. 2003;290:2292-3000.

55. Barter PJ, Caulfield M, Eriksson M, et al. Effects of torcetrapib in patients at high risk for coronary events. $N$ Engl J Med. 2007;357: 2109-2122.

56. Movva R, Rader DJ. Laboratory assessment of HDL heterogeneity and function. Clin Chem. 2008;54:788-800.

57. Salonen JT, Salonen R, Seppanen K, Rauramaa R, Tuomilehto J. HDL, HDL2, and HDL3 subfractions, and the risk of acute myocardial infarction. A prospective population study in eastern Finnish men. Circulation. 1991;84:129-139.

58. Lamarche B, Moorjani S, Cantin B, Dagenais GR, Lupien PJ, Despres JP. Associations of HDL2 and HDL3 subfractions with ischemic heart disease in men: prospective results from the Quebec Cardiovascular Study. Arterioscler Thromb Vasc Biol. 1997;17:1098-1105.

59. Stampfer MJ, Sacks FM, Salvini S, Willett WC, Hennekens CH. A prospective study of cholesterol, apolipoproteins, and the risk of myocardial infarction. $N$ Engl J Med. 1991;325:373-381.

60. Yu S, Yarnell JW, Sweetnam P, Bolton CH. High density lipoprotein subfractions and the risk of coronary heart disease: 9-years follow-up in the Caerphilly Study. Atherosclerosis. 2003;166:331-338.

61. Knopp RH, Alagona P, Davidson M, et al. Equivalent efficacy of a time-release form of niacin (Niaspan) given once-a-night versus plain niacin in the management of hyperlipidemia. Metabolism. 1998;47:1097-1104.

62. Viljoen A, WierzbickiAS. Potential options to treat hypertriglyceridaemia. Curr Drug Targets. 2009;10:356-362.

63. McBride PE. Triglycerides and risk for coronary heart disease. JAMA. 2007;298:336-338.

64. Garg A, Simha V. Update on dyslipidemia. J Clin Endocrinol Metab. 2007;92:1581-1589.

65. Austin MA, McKnight B, Edwards KL, et al. Cardiovascular disease mortality in familial forms of hypertriglyceridemia: A 20 -year prospective study. Circulation. 2000;101:2777-2782.

66. Brunzell JD. Clinical practice. Hypertriglyceridemia. N Engl J Med. 2007;357:1009-1017.

67. Mao EQ, Tang YQ, Zhang SD. Formalized therapeutic guideline for hyperlipidemic severe acute pancreatitis. World J Gastroenterol. 2003;9:2622-2626.

68. Tsimikas S, Brilakis ES, Miller ER, et al. Oxidized phospholipids, Lp(a) lipoprotein, and coronary artery disease. N Engl J Med. 2005;353: $46-57$. 
69. Danesh J, Collins R, Peto R. Lipoprotein(a) and coronary heart disease: meta-analysis of prospective studies. Circulation. 2000;102: 1082-1085.

70. Kamstrup PR, Tybjærg-Hansen A, Steffensen R, Nordestgaard BG. Genetically elevated lipoprotein(a) and increased risk of myocardial infarction. JAMA. 2009;301:2331-2339.

71. Clarke R, Peden JF, Hopewell JC, et al. Genetic variants associated with Lp(a) lipoprotein level and coronary disease. $N$ Engl J Med. 2009;361:2518-2528.

72. Kathiresan S. Lp(a) Lipoprotein redux - from curious molecule to causal risk factor. $N$ Engl J Med. 2009;361:2573-2574.

73. Martin SC, Viljoen A. The value of a specialist lipid clinic. Int J Clin Pract. 2008;62:961-966.

74. Kamanna VS, Ganji SH, Kashyap ML. Niacin: an old drug rejuvenated. Curr Atheroscler Rep. 2009;11:45-51.

75. Guyton JR. Niacin in cardiovascular prevention: mechanisms, efficacy and safety. Curr Opin Lipidol. 2007;18:415-420.

76. Carlson LA, Hanngren A. Initial distribution in mice of $3 \mathrm{H}-$ labelled nicotinic acid studied by autoradiography. Life Sci. 1964;3:867-871.

77. Wise A, Foord SM, Fraser NJ, et al. Molecular identification of high and low affinity receptors for nicotinic acid. J Biol Chem. 2003;278: 9869-9874.

78. Kamanna VS, Kashyap ML. Mechanism of action of niacin. Am J Cardiol. 2008;101:20B-26B.

79. Kamal-Bahl S, Burke T, Watson D, Wentworth C. Discontinuation of lipid modifying drugs among commercially insured United States patients in recent clinical practice. Am J Cardiol. 2007;99:530-534.

80. Knopp RH, Alagona P, Davidson M, et al. Equivalent efficacy of a time-release form of niacin (Niaspan) given once-a-night versus plain niacin in the management of hyperlipidemia. Metabolism. 1998;47:1097-1104.

81. Capuzzi DM, Guyton JR, Morgan JM, et al. Efficacy and safety of an extended-release niacin (Niaspan): a long-term study. Am J Cardiol. 1998;82:74U-81U.

82. Kashyap ML, McGovern ME, Berra K, et al. Long-term safety and efficacy of a once-daily niacin/lovastatin formulation for patients with dyslipidemia. Am J Cardiol. 2002;89:672-678.

83. McKenney JM, Jones PH, Bays HE, et al. Comparative effects on lipid levels of combination therapy with a statin and extended-release niacin or ezetimibe versus a statin alone (the COMPELL study). Atherosclerosis. 2007;192:432-437.

84. Kamanna VS, Ganji SH, Kashyap ML. The mechanism and mitigation of niacin-induced flushing. Int J Clin Pract. 2009:1369-1377.

85. Grundy SM, Vega GL, McGovern ME, et al; Diabetes Multicenter Research Group. Efficacy, safety, and tolerability of once-daily niacin for the treatment of dyslipidemia associated with type 2 diabetes: results of the assessment of diabetes control and evaluation of the efficacy of niaspan trial. Arch Intern Med. 2002;162:1568-1576.

86. Canner PL, Furberg CD, Terrin ML, McGovern ME. Benefits of niacin by glycemic status in patients with healed myocardial infarction (from the Coronary Drug Project). Am J Cardiol. 2005;95:254-257.
87. American Diabetes Association. Standards of medical care in diabetes - 2008. Diabetes Care. 2008;31:S12-S54.

88. American Diabetes Association. Management of dyslipidemia in adults with diabetes. Diabetes Care.1998;21:179-182.

89. National Institute for Health and Clinical Excellence. Diabetes - type 2 (update). [Online]. 2008 May [cited January 2010]; Available from URL: http://www.nice.org.uk/Guidance/CG66

90. Pike NB. Flushing out the role of GPR109A (HM74A) in the clinical efficacy of nicotinic acid. J Clin Invest. 2005;115:3400-3.

91. Thakkar RB, Kashyap ML, Lewin AJ, Krause SL, Jiang P, Padley RJ. Acetylsalicylic acid reduces niacin extended-release-induced flushing in patients with dyslipidemia. Am J Cardiovasc Drugs. 2009;9:69-79.

92. Auliffe M, Piechuta H, Nicoll-Griffith DA, et al. Discovery of a potent and selective prostaglandin D2 receptor antagonist, [(3R)-4(4-chloro-benzyl)-7-fluoro-5-(methylsulfonyl)-1,2,3,4-tetrahydrocyc lopenta[b]indol-3-yl]-acetic acid (MK-0524). J Med Chem. 2007;50: 794-806.

93. Van Hecken A, Depré M, De Lepeleire I, et al. The effect of MK-0524, a prostaglandin $\mathrm{D}(2)$ receptor antagonist, on prostaglandin D (2)-induced nasal airway obstruction in healthy volunteers. Eur $J$ Clin Pharmacol. 2007;63:135-141.

94. Bindhu K, Maria M, Scott B, et al. Absorption, metabolism, and excretion of [14C]MK-0524, a prostaglandin D2 receptor antagonist, in humans. Drug Metab Dispos. 2007;35:1196.

95. Lai E, Wenning LA, Crumley TM, et al. Pharmacokinetics, pharmacodynamics, and safety of a prostaglandin D2 receptor antagonist. Clin Pharmacol Ther. 2008;83:840-847.

96. Maccubbin D, Bays HE, Olsson Ag, et al. Lipid-modifying efficacy and tolerability of extended-release niacin/laropiprant in patients with primary hypercholesterolaemia or mixed dyslipidaemia. Int J Clin Pract. 2008;62:1959-1970

97. Gleim G, Ballantyne CM, Liu N, et al. Efficacy and safety profile of co-administered ER niacin/laropiprant and simvastatin in dyslipidaemia. Br J Cardiol. 2009;16:90-97.

98. Maccubbin D, Koren MJ, Davidson M, et al. Flushing profile of extended-release niacin/laropiprant versus gradually titrated niacin extended-release in patients with dyslipidemia with and without ischemic cardiovascular disease. Am J Cardiol. 2009;104:74-81.

99. Kush D, Hu DY, Ye P, et al. Flushing profile of extended-release niacin/laropiprant at initiation of therapy in Asian lipid clinic patients. Cardiology. 2009;114:192-198.

100. Hughes S. Experts speculate on Cordaptive rejection. [Online]. 2008 April 30 [cited January 2010]; Available from URL: http://www. theheart.org/article/860399.do.

101. Deyo RA. Gaps, tensions, and conflicts in the FDA approval process: implications for clinical practice. J Am Board Fam Pract. 2004; $17: 142-149$.

102. Rosen C. An Audience with. Clifford Rosen. Nat Rev Drug Discov. 2008;7:382.
Drug, Healthcare and Patient Safety

\section{Publish your work in this journal}

Drug, Healthcare and Patient Safety is an international, peer-reviewed open-access journal exploring patient safety issues in the healthcare continuum from diagnostic and screening interventions through to treatment, drug therapy and surgery. The journal is characterized by the rapid reporting of reviews, original research, clinical, epidemiological and

\section{Dovepress}

post-marketing surveillance studies, risk management, health literacy and educational programs across all areas of healthcare delivery. The manuscript management system is completely online and includes a very quick and fair peer-review system. Visit http://www.dovepress.com/ testimonials.php to read real quotes from published authors. 